\title{
T-cell receptor-HLA-DRB1 associations suggest specific antigens in pulmonary sarcoidosis
}

\author{
Johan Grunewald ${ }^{1}$, Ylva Kaiser ${ }^{1}$, Mahyar Ostadkarampour ${ }^{1}$, Natalia V. Rivera ${ }^{1}$, \\ Francesco Vezzi ${ }^{2}$, Britta Lötstedt ${ }^{3}$, Remi-André Olsen², Lina Sylwan ${ }^{3}$, \\ Sverker Lundin ${ }^{4}$, Max Käller ${ }^{4}$, Tatiana Sandalova ${ }^{5}$, Kerstin M. Ahlgren ${ }^{1}$, \\ Jan Wahlström ${ }^{1}$, Adnane Achour ${ }^{5}$, Marcus Ronninger ${ }^{1}$ and Anders Eklund ${ }^{1}$
}

\begin{abstract}
Affiliations: ${ }^{1}$ Respiratory Medicine Unit, Dept of Medicine, Solna and CMM, Karolinska Institutet and Karolinska University Hospital, Solna, Sweden. ${ }^{2}$ Science for Life Laboratory (SciLifeLab), Dept of Biochemistry and Biophysics, Stockholm University, Stockholm, Sweden. ${ }^{3}$ Science for Life Laboratory (SciLifeLab), Dept of Biosciences and Nutrition, Karolinska Institutet, Solna, Sweden. ${ }^{4}$ Science for Life Laboratory (SciLifeLab), Royal Institute of Technology (KTH), Gene Technology, Solna, Sweden. ${ }^{5}$ Science for Life Laboratory (SciLifeLab), Dept of Medicine, Solna, Karolinska Institutet, Stockholm, Sweden.
\end{abstract}

Correspondence: Johan Grunewald, Respiratory Medicine Unit, Department of Medicine Solna and CMM, Karolinska Institutet and Karolinska University Hospital, Lung Research Lab L4:01, Karolinska University Hospital, 17176 Solna, Sweden. E-mail: johan.grunewaldaki.se

ABSTRACT In pulmonary sarcoidosis, $\mathrm{CD}^{+}{ }^{+} \mathrm{T}$-cells expressing $\mathrm{T}$-cell receptor $\mathrm{V} \alpha 2.3$ accumulate in the lungs of $\mathrm{HLA}-\mathrm{DRB} 1^{\star} 03^{+}$patients. To investigate $\mathrm{T}$-cell receptor-HLA-DRB1 ${ }^{\star} 03$ interactions underlying recognition of hitherto unknown antigens, we performed detailed analyses of T-cell receptor expression on bronchoalveolar lavage fluid $\mathrm{CD} 4{ }^{+} \mathrm{T}$-cells from sarcoidosis patients.

Pulmonary sarcoidosis patients $(n=43)$ underwent bronchoscopy with bronchoalveolar lavage. T-cell receptor $\alpha$ and $\beta$ chains of $\mathrm{CD}^{+}$T-cells were analysed by flow cytometry, DNA-sequenced, and threedimensional molecular models of T-cell receptor-HLA-DRB1 ${ }^{\star} 03$ complexes generated.

Simultaneous expression of V $\alpha 2.3$ with the V $\beta 22$ chain was identified in the lungs of all HLA$\mathrm{DRB}^{\star}{ }^{\star} 3^{+}$patients. Accumulated V $\alpha 2.3 / \mathrm{V} \beta 22$-expressing $\mathrm{T}$-cells were highly clonal, with identical or near-identical V $\alpha 2.3$ chain sequences and inter-patient similarities in V $\beta 22$ chain amino acid distribution. Molecular modelling revealed specific T-cell receptor-HLA-DRB1*03-peptide interactions, with a previously identified, sarcoidosis-associated vimentin peptide, (Vim)429-443 DSLPLVDTHSKRTLL, matching both the HLA peptide-binding cleft and distinct T-cell receptor features perfectly.

We demonstrate, for the first time, the accumulation of large clonal populations of specific V $\alpha 2.3 / \mathrm{V} \beta 22$ $\mathrm{T}$-cell receptor-expressing $\mathrm{CD} 4^{+} \mathrm{T}$-cells in the lungs of $\mathrm{HLA}-\mathrm{DRB} 1^{\star} 03^{+}$sarcoidosis patients. Several distinct contact points between $\mathrm{V} \alpha 2.3 / \mathrm{V} \beta 22$ receptors and HLA-DRB1 ${ }^{\star} 03$ molecules suggest presentation of prototypic vimentin-derived peptides.

@ERSpublications

Clonal $\mathrm{CD}^{+}$lung T-cells associating with $\mathrm{HLA}-\mathrm{DRB} 1^{\star} 03$ molecules indicate specific antigens in pulmonary sarcoidosis http://ow.ly/UB81x

Editorial comment in: Eur Respir J 2016; 47: 707-709 [DOI: 10.1183/13993003.01791-2015].

This article has supplementary material available from erj.ersjournals.com

Received: July 242015 | Accepted after revision: Sept 302015 | First published online: Nov 192015

Support statement: Financial support in the form of research grants was received from The Swedish Heart Lung Foundation, The Swedish Research Council, The Mats Kleberg Foundation, The King Oscar II Jubilee Foundation, The Stockholm County Council, The Swedish Association for Chest Physicians, The Center for Inflammatory Diseases, and Karolinska Institutet. Funding information for this article has been deposited with FundRef.

Conflict of interest: None declared.

Copyright OERS 2016 


\section{Introduction}

$\mathrm{CD} 4{ }^{+} \mathrm{T}$-cells use clonally distributed $\alpha \beta$ T-cell receptors (TCRs) to recognise antigenic peptides bound to HLA-DR, -DP and -DQ molecules on the surface of antigen-presenting cells. The random combination of variable $(\mathrm{V})$, joining $(\mathrm{J})$ and, for the $\beta$ chain, diversity (D) gene segments and the similarly arbitrary addition and/or deletion of nucleotides at V-D-J junctions facilitate an extreme molecular diversity that underlies the unique antigen specificity of TCRs. Hypervariability primarily occurs in the complementarity-determining region (CDR) 3 loops, which constitute the main contact points for antigenic peptides presented by HLA molecules. V gene segments also contain germline-encoded CDR1 and CDR2 loops, which further mediate TCR recognition of peptide-HLA complexes by binding to the framework regions of HLA molecules, outside the peptide-binding groove [1].

In sarcoidosis, characteristic lung accumulations of T-cells expressing distinct TCR V $\alpha$ or V $\beta$ genes suggest the presence of specific antigens [2-4]. Lung-compartmentalised CD4 ${ }^{+} \mathrm{T}$-cells are highly activated [5] and produce T-helper (Th) type 1 cytokines $[6,7]$. More recently, an important role for Th17 [8] and regulatory T-cells Treg cells $[9,10]$ has also been implicated. We previously established that $\mathrm{V} \alpha 2.3^{+} \mathrm{CD} 4^{+}$ T-cells always accumulate in the lungs of HLA-DRB1 ${ }^{*} 0301^{+}$and HLA-DRB3 ${ }^{*} 0101^{+}$[11] sarcoidosis patients with active disease, but not in patients with other inflammatory pulmonary diseases, such as allergic alveolitis or asthma, nor in healthy individuals $[12,13]$. Earlier analyses of the TCR $\alpha$ chain of bronchoalveolar lavage (BAL) $\mathrm{V} \alpha 2.3^{+} \mathrm{CD} 4^{+} \mathrm{T}$-cells indicated selection towards specific antigens [14]. Interestingly, HLA-DRB $1^{\star} 0301$ and HLA-DRB $3^{\star} 0101$ molecules are structurally and functionally similar and seem to present a highly similar peptide antigen repertoire, including identical epitopes [15]. Hence, it is plausible that sarcoidosis-specific antigen(s) could be presented by either HLA-DRB1*0301 or HLA-DRB ${ }^{\star} 0101$ molecules, which may in turn be recognised by V $\alpha 2.3^{+}$T-cells [11].

In order to investigate the TCR V $\beta$ repertoire in BAL, we recently applied a panel of 21 TCR V $\beta$-specific antibodies, covering $70 \%$ of all $\mathrm{V} \beta$ gene segments, in sarcoidosis patients and healthy controls. Increased frequencies of $\mathrm{T}$-cells expressing $\mathrm{V} \beta 8, \mathrm{~V} \beta 16$, or $\mathrm{V} \beta 22$ were observed in the lungs of patients, and an association between lung-restricted V $\beta 22$ expansions and HLA-DRB1*03 ${ }^{+}$was identified [16].

Here, we therefore performed a comprehensive analysis of the association between HLA-DRB1 $03^{+}$ molecules and lung-accumulated $\mathrm{V} \alpha 2.3^{+} \mathrm{V} \beta 22^{+} \mathrm{CD}^{+} \mathrm{T}$-cells. Simultaneous expression of V $\alpha 2.3$ and V $\beta 22$ in BAL was assessed by flow cytometry, and such TCRs were further analysed by next-generation sequencing (NGS). We present a three-dimensional molecular model demonstrating hypothesised interactions between $\mathrm{V} \alpha 2.3 / \mathrm{V} \beta 22$ TCRs and HLA-DRB1*03 molecules, in line with specific antigen presentation. Finally, by combining sequencing data and molecular modelling, we are able to propose a potential candidate antigen in the form of cytoskeletal protein vimentin, a finding that implicates autoimmune processes in sarcoidosis aetiology.

\section{Materials and methods}

\section{Subjects, bronchoscopy and BAL}

Bronchoscopy with BAL was performed as previously described [17] on 43 patients (16 females) with recent disease onset and a median age of 39 years (table 1). There was a preference for inclusion of patients with Löfgren's syndrome, as they are more often HLA-DRB $1^{\star} 03^{+}$, which associates strongly with lung accumulations of T-cells expressing the TCR V $\alpha 2.3$ gene segment [13]. Löfgren's syndrome was defined in patients with an acute onset, usually with fever, chest radiographic findings with bilateral hilar lymphadenopathy, sometimes with pulmonary infiltrates, and with erythema nodosum and/or bilateral ankle arthritis. Thus, 26 patients had Löfgren's syndrome and 17 were classified as "non-Löfgren's syndrome" patients. All patients were HLA-typed (described in detail in the online data supplement) and diagnosed with sarcoidosis through typical clinical and radiographic manifestations, findings at bronchoscopy with BAL including an elevated CD4/CD8-ratio and positive biopsies (not required for diagnosing Löfgren's syndrome), in accordance with the criteria of the World Association of Sarcoidosis and other Granulomatous Disorders (WASOG) [18]. Written informed consent was obtained from all subjects and the Regional Ethical Review Board in Stockholm approved the study.

\section{Sorting of $\mathrm{V} \alpha 2.3^{+} \mathrm{V} \beta 22^{+} \mathrm{CD} 4^{+} \mathrm{BAL}$ T-cells and TCR $\alpha$ and $\beta$ gene amplification}

Phenotyping of $\mathrm{V} \alpha 2.3^{+} \mathrm{V} \beta 22^{+} \mathrm{T}$-cells by flow cytometry is described in the online data supplement. Expansions of lung T-cells expressing $\mathrm{V} \alpha 2.3$ and $\mathrm{V} \beta 22$ were defined based on their reference values of $3.5 \%$ [11] and $4.0 \%$ [16], respectively, in healthy individuals. The normal value of their co-expression was calculated to a median of $0.14 \%$ and the cut-off value for defining a $\mathrm{V} \alpha 2.3^{+} \mathrm{V} \beta 22^{+} \mathrm{T}$-cell expansion was set to $3 \times 0.14=0.42 \%$, thus approximated $0.5 \%$. In a subset of patients with $\mathrm{V} \alpha 2.3^{+} \mathrm{V} \beta 22^{+} \mathrm{CD} 4^{+} \mathrm{BAL}$ T-cell expansions, $\mathrm{V} \alpha 2.3^{+} \mathrm{V} \beta 22^{+}, \mathrm{V} \alpha 2.3^{+} \mathrm{V} \beta 22^{-}$or $\mathrm{V} \alpha 2.3^{-} \mathrm{V} \beta 22^{+} \mathrm{CD}^{+} \mathrm{BAL}$ cells were isolated through fluorescence-activated cell sorting (FACS), using a MoFlo XDP cell sorter (Beckman Coulter; Brea, CA, USA). 
TABLE 1 Clinical characteristics of the patient cohort with data shown for the entire patient group, as well as separately for HLA-DRB $1 * 03$ positive and negative patients

All patients HLA-DRB1*03 HLA-DRB1*03

positive patients negative patients

\begin{tabular}{|c|c|c|c|}
\hline Patients n & 43 & 26 & 17 \\
\hline \multicolumn{4}{|l|}{ Sex } \\
\hline Male & 27 & 15 & 12 \\
\hline Female & 16 & 11 & 5 \\
\hline Age years & $39.0(33.0-49.5)$ & $36.0(32.3-43.8)$ & $45.0(33.0-63.0)$ \\
\hline Löfgren's syndrome $n$ & 26 & 22 & 4 \\
\hline \multicolumn{4}{|l|}{ Chest radiographic stage ${ }^{\#}$} \\
\hline 0 & 0 & 0 & 0 \\
\hline । & 26 & 21 & 5 \\
\hline II & 14 & 5 & 9 \\
\hline III & 2 & 0 & 2 \\
\hline IV & 1 & 0 & 1 \\
\hline \multicolumn{4}{|l|}{ Smoking status } \\
\hline Non-smoker & 21 & 13 & 8 \\
\hline Former smoker & 15 & 8 & 7 \\
\hline Current smoker & 7 & 5 & 2 \\
\hline VC \% pred & $85.0(79.0-95.0)$ & $85.0(80.0-97.0)$ & $84.5(75.8-92.8)$ \\
\hline FEV $1 \%$ pred & $87.0(77.0-99.0)$ & $91.5(85.8-99.3)$ & $76.0(69.0-84.5)$ \\
\hline DLco \% pred & $86.0(73.0-95.0)$ & $87.0(77.0-97.5)$ & $84.0(74.3-92.0)$ \\
\hline BAL recovery $\%$ & $64.0(58.5-71.0)$ & $67.5(62.3-71.8)$ & $60.0(52.0-69.0)$ \\
\hline BAL cell concentration ${ }^{\pi} 10^{6}$ cells. $\mathrm{L}^{-1}$ & $212.6(116.7-321.3)$ & $183.4(129.3-300.8)$ & $279.4(108.8-364.9)$ \\
\hline Macrophages \% & $73.6(56.2-85.7)$ & $75.7(64.1-88.3)$ & $66.3(49.2-79.6)$ \\
\hline Lymphocytes \% & $25.0(12.2-40.4)$ & $19.2(10.2-32.1)$ & $32.0(18.6-49.0)$ \\
\hline Neutrophils \% & $1.4(0.7-2.2)$ & $1.6(0.7-2.3)$ & $1.3(0.8-1.6)$ \\
\hline Eosinophils \% & $0.2(0.0-0.6)$ & $0.1(0.0-0.6)$ & $0.2(0.0-0.6)$ \\
\hline BAL CD4/CD8 ratio & 9.2 (5.3-17.5) & $12.9(6.3-20.7)$ & $7.2(3.6-12.0)$ \\
\hline
\end{tabular}

Data are presented as median (interquartile range), unless otherwise stated. VC: vital capacity; FEV1: forced expiratory volume in $1 \mathrm{~s}$; DLCO: diffusing capacity of the lung for carbon monoxide; BAL: bronchoalveolar lavage. " : chest radiography staging as follows: stage 0: normal chest radiography; stage I: enlarged lymph nodes; stage II: enlarged lymph nodes with parenchymal infiltrates; stage III: parenchymal infiltrates without enlarged lymph nodes; and stage IV signs of pulmonary fibrosis. ๆ: BAL basophils and mast cells were excluded from the cell differential counts.

In a second subset of patients, we opted to use unsorted BAL cells as a means of avoiding cell distortion and mRNA damage that may occur during sorting. Due to the notable expansions of $\mathrm{V} \alpha 2.3^{+} \mathrm{V} \beta 22^{+} \mathrm{CD} 4^{+}$ T-cells, TCR V $\alpha 2.3$ and V $\beta 22$ chain mRNA should be present at high enough levels to be obtainable irrespective of sorting. The highly similar results showed both approaches (i.e. with or without prior FACS sorting) to be equally successful.

PCR amplification of $\mathrm{V} \alpha 2.3$ and $\mathrm{V} \beta 22$ genomic regions, respectively, was performed using a specific variable region oligonucleotide forward primer and a conserved constant region reverse primer for each TCR chain. Detailed mRNA extraction protocols, PCR conditions and primer information are provided in the online data supplement.

\section{Statistical analysis}

Relative numbers of $\mathrm{V} \alpha 2.3^{+}$and $\mathrm{V} \beta 22^{+}$BAL T-cells (expressed as percent of all CD4 ${ }^{+}$BAL T-cells) were calculated and compared between patient groups based on the presence or absence of distinct HLA-DRB1 and HLA-DRB3 alleles, respectively, using the two-tailed non-parametric Mann-Whitney U-test. A two-tailed Wilcoxon's signed rank test was applied for paired comparisons of $\mathrm{V} \alpha 2.3^{+} \mathrm{V} \beta 22^{+}$versus V $\alpha 2.3^{-} \mathrm{V} \beta 22^{-} \mathrm{CD}^{+}$T-cells. Analyses were performed using GraphPad Prism v.5.02 software (GraphPad Software Inc., La Jolla, CA, USA), and $\mathrm{p}<0.05$ was considered significant.

DNA-sequencing and de novo transcript assembly

NGS was performed with the Illumina Nextera XT kit (Illumina, San Diego, CA, USA) according to protocol except for necessary modifications for adaption to the Agilent NGS workstation with MiSeq $2 \times 250$ sequencing (Agilent, Santa Clara, CA, USA). Additional details regarding the method and 
subsequent bioinformatics analysis is provided in the online data supplement. De novo transcript assembly and primary transcript analysis were performed using Trinity $[19,20]$.

Three-dimensional molecular modelling of ternary TCR/DRB1*0301/peptide complexes V $\alpha 2.3 / V \beta 22$ TCR sequences were retrieved from the IMGT (International ImMunoGeneTics Information System) database [21], and all modelling was performed manually using the COOT program [22]. A detailed description of the modelling procedure is provided in the online data supplement.

\section{Results}

TCRs of lung-accumulated T-cells in HLA-DRB $1 * 03^{+}$sarcoidosis patients

In HLA-DRB $1^{\star} 03^{+}$patients, we verified previous findings of large populations of lung-accumulated CD $4^{+}$ T-cells expressing the TCR V 22.3 gene segment, constituting $33.3 \%$ (median) of all CD4 ${ }^{+}$BAL T-cells (figure $1 \mathrm{a}$ and table 2 ). In HLA-DRB1 ${ }^{*} 03^{-}$patients, the corresponding median value was $5.2 \%$, including six patients with close to $20 \%$ of $\mathrm{BAL} \mathrm{CD} 4^{+}$T-cells expressing V $\alpha 2.3^{+}$(figure 1a and table S2). These patients were found to be HLA-DRB1 ${ }^{\star} 03^{-}$but HLA-DRB3 ${ }^{*} 01^{+}$(tables S1 and S2). TCR VB22 ${ }^{+}$T-cells were also found to accumulate in the lungs of HLA-DRB $1^{\star} 03^{+}$patients, with a median value of $9.2 \%$ of all BAL CD4 ${ }^{+}$T-cells, compared with $2.3 \%$ in HLA-DRB1*03- patients (table 2 ).

Simultaneous expression of V $\alpha 2.3$ and V $\beta 22$ gene segments was found in $6.2 \%$ of all BAL CD4 ${ }^{+}$T-cells in HLA-DRB ${ }^{\star} 03^{+}$, compared with $0.3 \%$ in HLA-DRB1 ${ }^{\star} 03^{-}$patients (figure $1 \mathrm{~b}$ and $\mathrm{c}$, and table 2). No difference could be observed between men and women in terms of V $\alpha 2.3 / \mathrm{V} \beta 22$ expression. Moderate $\mathrm{V} \alpha 2.3^{+} \mathrm{V} \beta 22^{+}$BAL T-cell expansions were found in some HLA-DRB1 ${ }^{\star} 03^{-}$patients (figure $1 \mathrm{~b}$ and $\mathrm{c}$ ); these
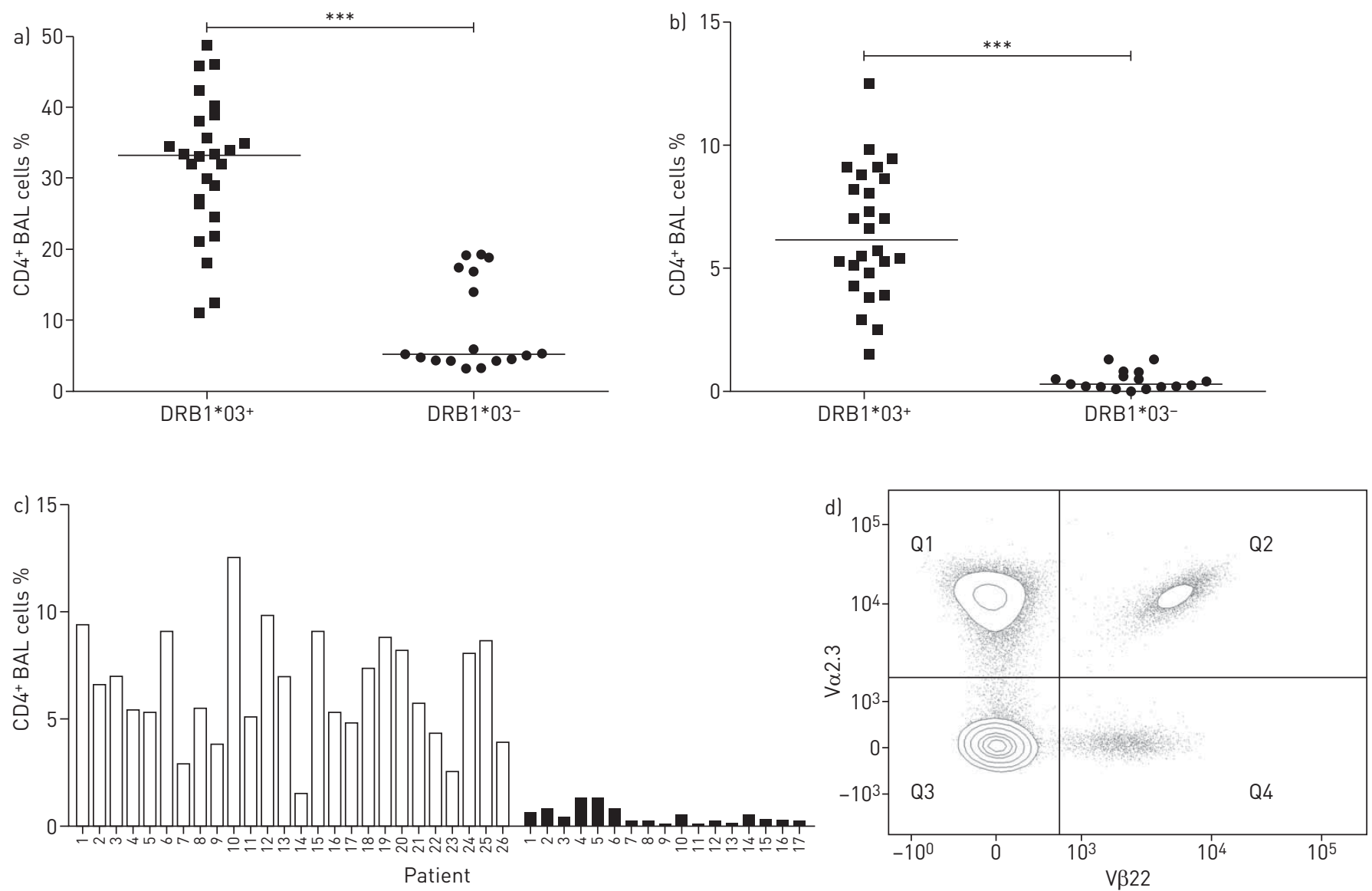

FIGURE $1 \mathrm{~V} \alpha 2.3^{+} \mathrm{V} \beta 22^{+} \mathrm{CD}^{+} \mathrm{T}$-cells accumulate in the lungs of $\mathrm{HLA}-\mathrm{DRB} 1{ }^{*} 03^{+}$patients with pulmonary sarcoidosis. a, b) Relative numbers of bronchoalveolar lavage (BAL) CD4 $4^{+}$-cells expressing T-cell receptor (TCR) V $\alpha 2.3$ (a) or TCR V $\alpha 2.3 / \mathrm{V} \beta 22$ (b) in DRB ${ }^{*} 03^{+}$( $\mathrm{n}=26$ ) or $\mathrm{DRB} 1{ }^{*} 03^{-}$ patients ( $n=17$ ), respectively. ${ }^{* * *}: p<0.0001$ (Mann-Whitney $U$ test). c) Comparison of the percentage of $\mathrm{CD} 4^{+} \mathrm{T}$-cells in $\mathrm{BAL}$ fluid that are $\mathrm{V} \alpha 2.3^{+}$ $\mathrm{V} \beta 22^{+}$in $\mathrm{DRB} 1{ }^{*} 03^{+}$patients $\left(1-26\right.$, open bars) and in DRB ${ }^{*} 03^{-}$patients $(1-17$, black bars), respectively, showing a significantly higher frequency of $\mathrm{V} \alpha 2.3^{+} \mathrm{V} \beta 22^{+} \mathrm{CD}^{+}$T-cells in HLA-DRB ${ }^{*} 03^{+}$than $\mathrm{HLA}-\mathrm{DRB} 1{ }^{*} 03^{-}$patients. d) Representative contour plot of the $\mathrm{V} \alpha 2.3^{+} \mathrm{V} \beta 22^{+} \mathrm{T}-\mathrm{cell}$ population in a $\mathrm{DRB} 1 *{ }^{*} 3^{+}$sarcoidosis patient, as detected by multi-colour flow cytometry (Becton-Dickinson, San Jose, CA, USA). Cells are gated on CD3 ${ }^{+} \mathrm{CD} 4^{+}$ lymphocytes, and populations were distributed as follows: Q1 20.8\%, Q2 5.3\%, Q3 71.0\% and Q4 2.9\%. 
TABLE 2 Summary of all bronchoalveolar lavage (BAL) $C D 4^{+} \mathrm{T}$-cells that express $\mathrm{V} \alpha 2.3, \mathrm{~V} \beta 22$, and $\mathrm{V} \alpha 2.3$ together with $\mathrm{V} \beta 22$; the percentage of $\mathrm{V} \alpha 2.3^{+} \mathrm{CD} 4^{+} \mathrm{BAL} \mathrm{T}$-cells that express $\mathrm{V} \beta 22$, and the percentage of $\mathrm{V} \beta 22^{+} \mathrm{CD}^{+}$BAL T-cells that express $\mathrm{V} \alpha 2.3$ are also stated

\begin{tabular}{|c|c|c|c|}
\hline & All patients & $\begin{array}{l}\text { HLA-DRB } 1 * 03 \\
\text { positive patients }\end{array}$ & $\begin{array}{c}\text { HLA-DRB } 1 * 03 \\
\text { negative patients }\end{array}$ \\
\hline Patients n & 43 & 26 & 17 \\
\hline Vo2.3+ BAL CD4+ T-cells \% & $21.8(8.5-33.7)$ & $33.3(26.5-37.4)$ & $5.2(4.3-16.8)$ \\
\hline VB22+ BAL CD4+ T-cells \% & $6.0(3.1-9.8)$ & $9.2(7.7-11.5)$ & $2.3(1.4-3.2)$ \\
\hline Vo2.3+/Vß22+ BAL CD4+ T-cells \% & $3.9(0.5-7.0)$ & $6.2(4.9-8.5)$ & $0.3(0.2-0.6)$ \\
\hline $\begin{array}{l}\text { V } \alpha 2.3+\text { CD } 4+\text { BAL T-cells that } \\
\text { express V } \beta 22 \%\end{array}$ & $13.7(6.6-22.9)$ & $21.0(16.2-25.6)$ & $4.2(2.9-8.0)$ \\
\hline $\begin{array}{l}\text { V } \beta 22+C D 4+B A L T \text {-cells that express } \\
\text { V } 22.3 \%\end{array}$ & $46.7(10.7-61.8)$ & $62.3(59.7-69.2)$ & $9.7(6.6-13.0)$ \\
\hline
\end{tabular}

Data are presented as median (interquartile range), unless otherwise stated. All figures are shown for the entire patient group as well as for patients with or without HLA-DRB1*03.

patients were found to be $\mathrm{DRB} 1^{\star} 03^{-} \mathrm{DRB}^{\star} 01^{+}$. Relative percentages of $\mathrm{V} \alpha 2.3^{+} \mathrm{V} \beta 22^{+} \mathrm{CD} 4^{+} \mathrm{BAL}$-cells in $\mathrm{DRB} 1^{\star} 03^{+}, \mathrm{DRB} 1^{\star} 03^{-} / \mathrm{DRB} 3^{\star} 01^{+}$, and $\mathrm{DRB} 1^{\star} 03^{-} \mathrm{DRB} 3^{\star} 01^{-}$patients, respectively, are presented in figure S1 and table S2. In HLA-DRB ${ }^{\star} 03^{+}$patients, $21.0 \%$ of $\mathrm{V} \alpha 2.3^{+}$lung T-cells simultaneously expressed $\mathrm{V} \beta 22$, while $62.3 \%$ of $\mathrm{V} \beta 22^{+} \mathrm{T}$-cells also expressed $\mathrm{V} \alpha 2.3$ (table 2 and figure S2). Representative flow cytometry staining plots of $\mathrm{V} \alpha 2.3^{+} \mathrm{V} \beta 22^{+} \mathrm{T}$-cells are shown in figure $1 \mathrm{~d}$ and figure S2.

\section{$V \alpha 2.3^{+} V \beta 22^{+} B A L T$-cells differ with regard to phenotype}

The lung-accumulated $\mathrm{V} \alpha 2.3^{+} \mathrm{V} \beta 22^{+}$T-cell population expressed significantly higher levels of lymphocyte activation marker CD69 compared to $\mathrm{V} \alpha 2.3^{-} \mathrm{V} \beta 22^{-}$T-cells within the same individual, as assessed by flow cytometry (figure 2a). Furthermore, significantly fewer $\mathrm{V} \alpha 2.3^{+} \mathrm{V} \beta 22^{+} \mathrm{T}$-cells expressed CD27, which is lost upon prolonged activation and differentiation, compared to autologous $\mathrm{V} \alpha 2.3^{-} \mathrm{V} \beta 22^{-} \mathrm{T}$-cells (figure $2 \mathrm{~b}$ ).

\section{V $\alpha 2.3^{+} V \beta 22^{+}$BAL T-cells are derived from a few dominant clones}

TCR $\alpha$ and $\beta$ chains were sequenced using specific primers for $\mathrm{V} \alpha 2.3$ and V $\beta 22$ in combination with $\mathrm{C} \alpha$ and $\mathrm{C} \beta$ chains, respectively. In patients $1-4$ and $8-10$, lung-accumulated $\mathrm{V} \alpha 2.3^{+} \mathrm{V} \beta 22^{+} \mathrm{CD} 4^{+} \mathrm{T}$-cell populations were FACS-sorted before sequencing, while in patients 5-7 and patient 11, total BAL cells (containing $\mathrm{V} \alpha 2.3^{+} \mathrm{V} \beta 22^{+} \mathrm{T}$-cell expansions) were used. In patients $8-11$, the mRNA concentration was too low to enable PCR amplification of the V $\beta 22$ chain (table 3). In addition, in patients 2, 3, 12 and 13, FACS-sorted V $\alpha 2.3^{+} \mathrm{V} \beta 22^{-} \mathrm{T}$-cells and $\mathrm{V} \alpha 2.3^{-} \mathrm{V} \beta 22^{+}$were sequenced (table S3).

In all 13 cases, 1-4 dominant sequences were identified for the highly variable CDR3 region in any given patient, and in three patients only one dominant $\alpha$ chain sequence was observed (figure 3, table 3 and table S3).
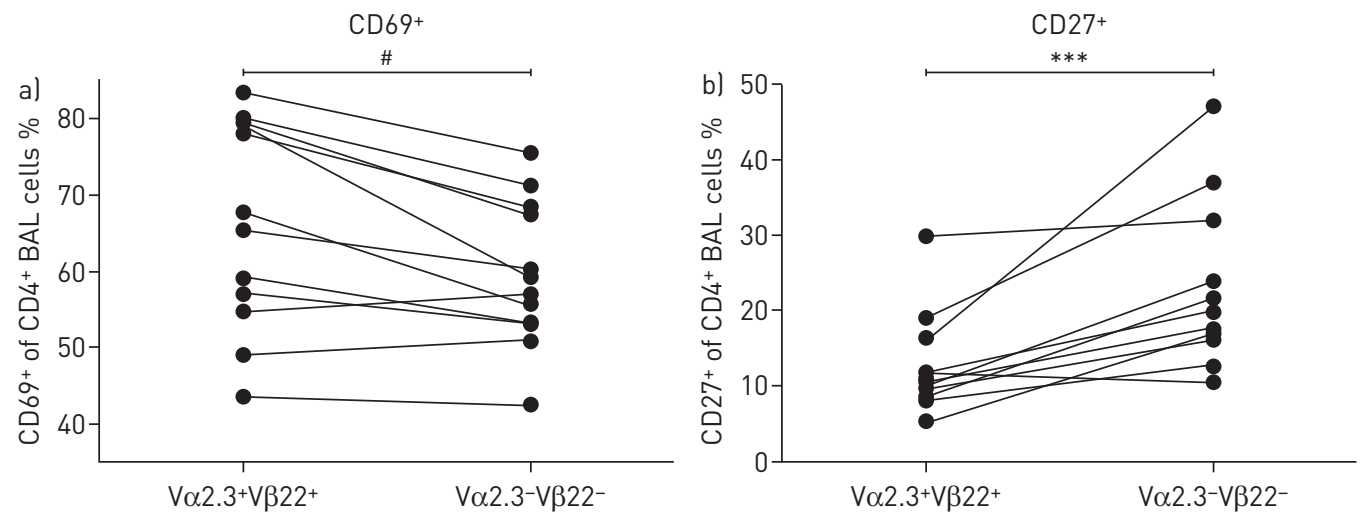

FIGURE $2 \mathrm{~V} \alpha 2.3^{+} \mathrm{V} \beta 22^{+} \mathrm{CD}^{+} \mathrm{T}$-cells have a higher activation and differentiation state than autologous

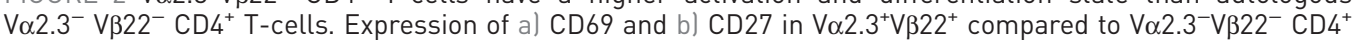
bronchoalveolar lavage (BAL) T-cells from the same individual $(n=12)$. Populations are expressed as percent of $\mathrm{CD}^{+} \mathrm{CD}^{+} \mathrm{V} \alpha 2.3^{+} \mathrm{V} \beta 22^{+}$or $\mathrm{V} \alpha 2.3^{-} \mathrm{V} \beta 22^{-}$BAL lymphocytes. ${ }^{\#}: \mathrm{p}=0.0049$; $^{* * *}$ : $\mathrm{p}=0.001$ using Wilcoxon's signed rank test. 
TABLE 3 Patients' T-cell receptor V $\alpha 2.3$ and V $\beta 22$ amino acid sequences determined by next-generation sequencing (NGS)

\begin{tabular}{|c|c|c|c|c|c|c|c|c|c|}
\hline \multirow[t]{2}{*}{ Patient } & \multirow[t]{2}{*}{ HLA-type } & \multicolumn{4}{|c|}{ Vo2.3 } & \multicolumn{4}{|c|}{ V $\beta 22$} \\
\hline & & Amino acid sequence & Frequency $\%$ & TRAJ & CDR3 length & Amino acid sequence & Frequency $\%$ & TRBJ & CDR3 length \\
\hline \multirow[t]{2}{*}{1} & $\mathrm{DRB} 1 * 03,16$ & CVVNTPGNTPLVF & 50.93 & $29 * 01 \mathrm{~F}$ & 11 & CASSEQGRGETQYF & 59.8 & $2-5 * 01$ & 12 \\
\hline & & CVVNMGNTGGFKTIF & 49.07 & $9 * 01 \mathrm{~F}$ & 13 & CASSGTSVSTGELFF & 32.1 & $2-2 * 01$ & 13 \\
\hline \multirow[t]{3}{*}{2} & $\mathrm{DRB} 1 * 03,01$ & CVVNIGYGNKLVF & 32.75 & $47 * 01 \mathrm{~F}$ & 11 & CASSGPGGRTEAFF & 36.02 & $1-1 * 01$ & 12 \\
\hline & & CVVSVQGAQKLVF & 23.82 & $54 * 01 \mathrm{~F}$ & 11 & CASSEMTRVVFHF & 53.35 & $1-6 * 01$ & 11 \\
\hline & & CVVNGLNIGDSGGGADGLTF & 43.43 & $45^{*} 01 \mathrm{~F}$ & 18 & CASSVITSGELFF & 7.53 & $2-2 * 01$ & 11 \\
\hline \multirow[t]{3}{*}{3} & DRB1*03,13 & CVVNNYKLSF & 100 & $20 * 01 \mathrm{~F}$ & 8 & CASSGTGGAGTEAFF & 31.56 & $1-1 * 01$ & 13 \\
\hline & & & & & & CASSEDVGRGAAFF & 34.49 & $1-1 * 01$ & 12 \\
\hline & & & & & & CASSGGFEQYF & 33.1 & $2-7 * 01$ & 9 \\
\hline \multirow[t]{3}{*}{4} & $\mathrm{DRB} 1 * 03,08$ & CVVNMGRGGSNYKLTF & 33.92 & $53 * 01 \mathrm{~F}$ & 14 & CASSGGHGKGEQFF & 50.87 & $2-1 * 01$ & 12 \\
\hline & & CVVGINNRKLIW & 21.48 & $38 * 01 \mathrm{~F}$ & 10 & CASSGAGGRGNEQFF & 31.49 & $2-1 * 01$ & 13 \\
\hline & & CVVNVRPGNTPLVF & 44.6 & $29 * 01 \mathrm{~F}$ & 12 & no CDR3 & 14.29 & no J & - \\
\hline \multirow[t]{2}{*}{5} & DRB1*03,11 & CVVNLAGNQFYF & 80.93 & $49 * 01 \mathrm{~F}$ & 10 & CASSVSTDTQYF & 39.75 & $2-3 * 01$ & 10 \\
\hline & & CVVNPLGGGSYIPTF & 19.07 & 6*01 F & 13 & CASSEFGQGGHEQYF & 60.25 & $2-7 * 01$ & 13 \\
\hline \multirow[t]{3}{*}{6} & $\mathrm{DRB} 1 * 03,04$ & CVVKEGSYIPTF & 21.79 & $6 * 01 \mathrm{~F}$ & 10 & CASSIDRSVGEKLFF & 37.69 & $1-4^{*} 01$ & 13 \\
\hline & & CAVKSGNNRLAF & 14.38 & $7 * 01 \mathrm{~F}$ & 10 & CASSGTARNYGYTF & 60.94 & $1-2 * 01$ & 12 \\
\hline & & CVVNMEYGNKLVF & 63.82 & $47 * 01 \mathrm{~F}$ & 11 & & & & \\
\hline \multirow[t]{4}{*}{7} & $\mathrm{DRB} 1 * 03,13$ & CVVIGSGGSQGNLIF & 53.45 & $42 * 01 \mathrm{~F}$ & 13 & CASSAITSNEKLFF & 5.84 & $1-4^{*} 01$ & 12 \\
\hline & & CVVNLAGNQFYF & 46.55 & $49 * 01 \mathrm{~F}$ & 10 & CASSAGSGQPQHF & 23.47 & $1-5^{*} 01$ & 11 \\
\hline & & & & & & CASRPTSGRSDEQFF & 10.35 & $2-1 * 01$ & 13 \\
\hline & & & & & & CASSVLGTAAVTF & 60.35 & $2-6 * 01$ & 11 \\
\hline \multirow[t]{3}{*}{8} & DRB1*03,08 & CVVISGSARQLTF & 24.38 & $22 * 01 \mathrm{~F}$ & 11 & & & & \\
\hline & & CVVNIAGNQFYF & 33.97 & $49 * 01 \mathrm{~F}$ & 10 & & & & \\
\hline & & CVVNPSGTYKYIF & 41.65 & $40 * 01 \mathrm{~F}$ & 11 & & & & \\
\hline 9 & $\mathrm{DRB} 1 * 03,13$ & CVVNMGNQAGTALIF & 100 & $15^{*} 01 \mathrm{~F}$ & 13 & & & & \\
\hline \multirow[t]{2}{*}{10} & $\mathrm{DRB} 1 * 03,04$ & CVVNGHSNYQLIW & 42.4 & $33 * 01 \mathrm{~F}$ & 12 & & & & \\
\hline & & CVVNRATGNQFYF & 57.6 & $49 * 01 \mathrm{~F}$ & 11 & & & & \\
\hline 11 & $\mathrm{DRB} 1 * 03,07$ & CVVNTGFQKLVF & 100 & $8 * 01 \mathrm{~F}$ & 10 & & & & \\
\hline
\end{tabular}

Frequency refers to the percentage of reads mapped to every given transcript (isoforms with $>10 \%$ frequency). In cases where the total percentage is $<100 \%$, the remaining sequences were either too short or did not align. The designations TRAJ and TRBJ follow the IMGT (International ImMunoGeneTics Information System) T-cell receptor gene nomenclature. Length of CDR3 region as derived from the IMGT database. All cells were derived from HLA DRB $1 *^{*} 03^{+}$patients with bronchoalveolar lavage (BAL) V $\alpha 2.3^{+} \mathrm{V} \beta 22^{+} \mathrm{CD} 4^{+} \mathrm{T}$-cell expansions. For patients 1-4 and 8-10, mRNA was extracted from fluorescence-activated cell sorting V $\alpha 2.3^{+} V \beta 22^{+}$T-cells. For patients 5-7 and 11 , mRNA was extracted from unsorted BAL cells. For patients 8-11, the amount of product obtained for the V $\beta 22$ chain following PCR amplification was too low to yield reliable sequencing data. V $\alpha 2.3$ sequences (highlighted in bold font) share the $49 * 01 \mathrm{~J}$ segment and identical or near-identical amino acid sequences. 


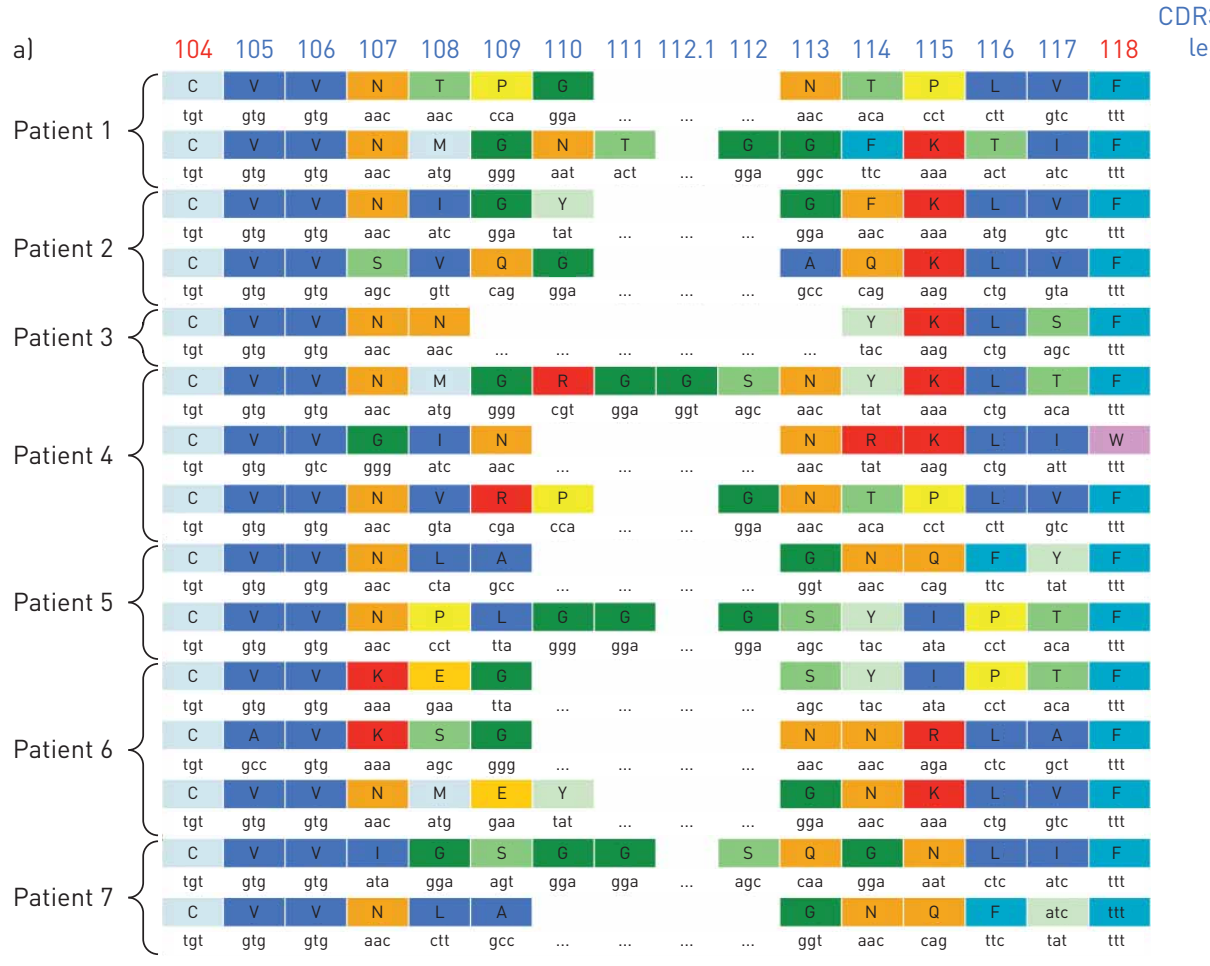

CDR3-IMGT Molecular

Mass

$11 \quad 1360.6$

$13 \quad 1587.88$

11

1425.72

1377.67

1186.4

1746.04

1414.74

1514.81

1374.58

13

1523.77

10

1342.58

10

1279.49

11

1515.82

13

1450.68

10

1374.58

b)

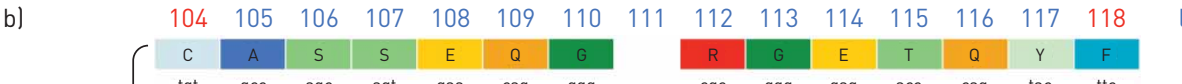

CDR3-IMGT Molecular

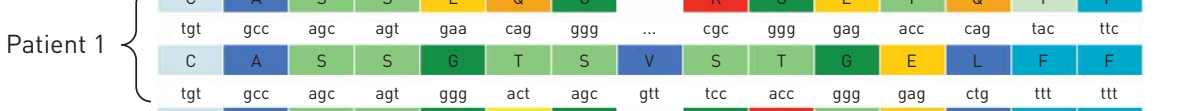
\begin{tabular}{c|ccc|c|c|c|c|c|c|c|c|c|c|c|c|c|c|} 
tgt & gcc & agc & agt & ggg & act & agc & gtt & tcc & acc & ggg & gag & ctg & ttt & ttt \\
\hline C & A & S & S & $G$ & P & $G$ & $\ldots$ & $G$ & R & T & E & A & F & F \\
\hline tgt & gcc & agc & agt & ggt & cca & ggg & $\ldots$ & ggg & aga & acc & gaa & gct & ttc & ttt \\
\hline
\end{tabular} Patient 2 $\left\{\begin{array}{cc|c|c|c|c|c|c|c|c|c|c|c|c|c|}\text { tgt } & \text { gcc } & \text { agc } & \text { agt } & \text { ggt } & \text { cca } & \text { ggg } & \cdots & \text { ggg } & \text { aga } & \text { acc } & \text { gaa } & \text { gct } & \text { ttc } & \text { ttt } \\ \hline \text { C } & \text { A } & \text { S } & \text { S } & \text { E } & \text { M } & \text { T } & \cdots & \cdots & \text { R } & \text { V } & \text { V } & \text { F } & \text { H } & \text { F } \\ \hline \text { tgt } & \text { gcc } & \text { agc } & \text { agt } & \text { gaa } & \text { atg } & \text { act } & \cdots & \cdots & \text { cgg } & \text { gtg } & \text { gtc } & \text { ttc } & \text { cac } & \text { ttt } \\ \hline \text { C } & \text { A } & \text { S } & \text { S } & \text { V } & \text { I } & \text { T } & \cdots & \cdots & \text { S } & \text { G } & \text { E } & \text { L } & \text { F } & \text { F } \\ \hline\end{array}\right.$

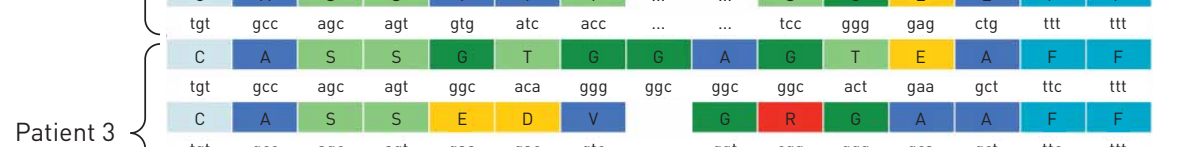

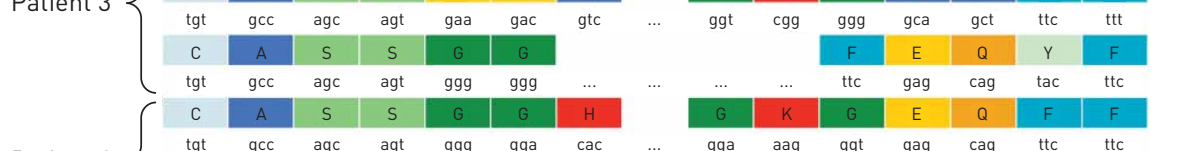

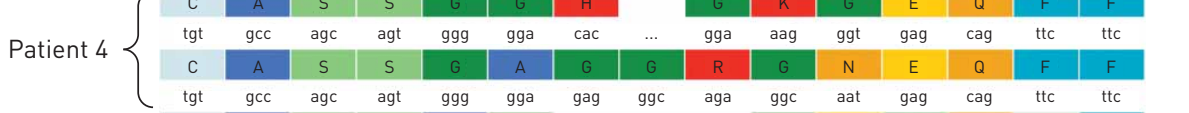

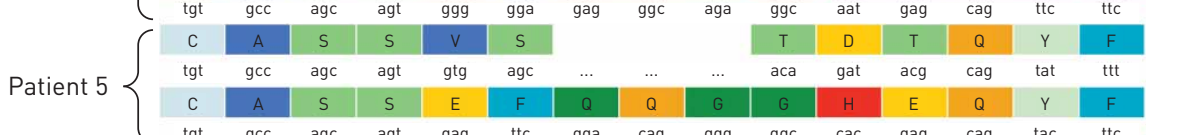
Mass

$12-1562.64$

FIGURE 3 T-cell receptor (TCR) CDR3 region sequences and amino acid delineation of seven DRB $1 * 03^{+}$patients show inter-patient similarities in amino acid positioning and properties. TCR CDR3 region alignment was performed for the TCR $\alpha$ and $\beta$ chains of the patients from whom sequencing data could be obtained for both chains. Patients 1-7 correspond to patients 1-7 in table 3. a) V $\alpha 2.3$ CDR3 sequences and b) V $\beta 22$ CDR3 sequences from the same patients are shown. Figures were generated with tools made available by IMGT (International ImMunoGeneTics Information System), and amino acid positions and chemical properties demarcated according to the IMGT definition. 
In six patients, identical or near-identical $\alpha$ chain CDR3 region sequences were identified, all expressing the same J $\alpha$ gene segment $49^{*} 01$ (table $3 \mathrm{~A}$ and table S3). Specifically, the identical CDR3 amino acid sequence CVVNLAGNQFYF was observed in patients 5 and 7, and near-identical CDR3 amino acid sequences CVVNIAGNQFYF, CVVNRATGNQFYF, CVVNMAGNQFYF and CVVNPGTGNQFYF in patients 8, 10, 12 and 3, respectively (in the latter two cases from $\mathrm{V} \alpha 2.3^{+} \mathrm{V} \beta 22^{-}$-sorted $\overline{\mathrm{BAL}} \mathrm{T}$-cells; table S3). Of note, the leucine residue (L) at CDR3 position 108 is conservatively replaced by an isoleucine (I) in patient 8 and by a methionine $(\mathrm{M})$ in patient 12 . Furthermore, the leucine residue at position 108 of the identical CDR3 amino acid sequences shared between patients 5 and 7 was encoded by two different nucleotide sequences ("CTA" in patient 5 and "CTT" in patient 7, respectively) (figure 3a and table S4A). Likewise, in patients 1, 2, 3, 4 and 6, the lysine residue at position 115 was coded for by AAG or AAA.

For the $\beta$ chains, we found 2-4 dominating clonal sequences in each individual patient, frequently with a preferred expression of $J \beta$ gene segment $2-1^{\star} 01$ (found in four out of seven patient samples) (figure $3 \mathrm{~b}$ and table 3 ). A positively charged arginine was found significantly more often at position 112 in the $\beta$ chains of several patients (four out of 18 sequences, $22 \%$ ) compared with published reference $\beta$ chain sequences retrieved from IMGT/LIGM-DB [23] (one $(1 \%)$ out of $73 ; \mathrm{p}<0.001$ ). In line with this finding, positively charged arginine or lysine amino acid residues at positions 112 or 113 appeared more frequently in our samples (eight (44\%) out of 18 sequences, compared to nine (12\%) out of 73 in reference $\beta$ chain sequences; $\mathrm{p}<0.001$ ) (figure $3 \mathrm{~b}$ and figure S3). Finally, a negatively charged glutamic acid tended to appear at position 115 more often than in reference sequences $(p=0.09)$. In addition, several of these identical amino acids were encoded by different nucleotide combinations (arginine at position 112-113 and glutamate at position 115, respectively), indicating an important role in specific interactions between these residues and HLA-DRB1 ${ }^{\star} 03^{+}$molecules, as well as with HLA-restricted antigens (figure $3 \mathrm{~b}$ and table S4B).

\section{A three-dimensional molecular model of the Vo2.3 $\mathrm{VB22}{ }^{+} \mathrm{TCR}$ implicates specific residues for recognition of HLA-DRB $1 * 03$ molecules and a vimentin-derived peptide}

No structural information has hitherto been provided for TCRs of the V $\alpha 2.3 / \mathrm{V} \beta 22$ class. An ensemble of three-dimensional molecular models of ternary TCR/HLA/peptide complexes was created based on the CDR loops derived from obtained sequencing results for patient TCRs. The proposed three-dimensional molecular model for the V $\alpha 2.3 / \mathrm{V} \beta 22 \mathrm{TCR}$ in complex with HLA-DRB1 ${ }^{\star} 03$ (figure 4a) revealed that the glycine and asparagine residues Gly73 and Asn77, unique for HLA-DRB1 ${ }^{\star} 03$, may play a key role through possible interactions with TCR residues Gln30 and Ser51 localised on the CDR1 $\alpha$ and CDR2 $\alpha$ loops, respectively (figure 4b). Moreover, the presence of a basic arginine (or lysine) residue at position 112 or 113 in close to half of the sequenced CDR3 $\beta$ loops enables interaction with negatively charged HLA-DRB1 ${ }^{\star} 03$ residues Asp66 or Glu69 (figure 4c), or with a negatively charged or polar residue localised in the middle of the presented peptide. In addition to these observations, the model also indicated that V $\beta 22$ residue Glu115, found in nearly all patients, may be important for selection of the $V \alpha 2.3$ chain through specific interactions with residues Ser31 and Tyr50 localised on V $\alpha 2.3$ CDR1 $\alpha$ and CDR2 $\alpha$ loops, respectively (figure 4b).

Based on these findings and our previous discoveries regarding the vimentin-derived peptide Vim429-443 (DSLPLVDTHSKRTLL) [24], we hypothesised that vimentin could bind to HLA-DRB1 ${ }^{\star} 3$ by using residues Leu433, Thr436, Ser438 and Thr441 as anchor positions and consequently occupying pockets 1, 4, 6 and 9 respectively. Other features, including peptide residues Asp435, His437 and Arg440 that can interact with TCR CDR3 $\beta$ residues Arg112 and Glu114, were also observed (figure 4d).

\section{Discussion}

Previous studies on TCR V $\alpha 2.3^{+}$T-cells in sarcoidosis have not considered paired V $\beta$ gene expression. In early attempts, PCR techniques were applied to address this question, but without any distinct findings [14]. Using new techniques, we initially found a higher-than-normal usage of V $\beta 22$ in lung-accumulated T-cells from HLA-DRB $1^{\star} 03^{+}$patients [16], and in the present report further establish that a substantial

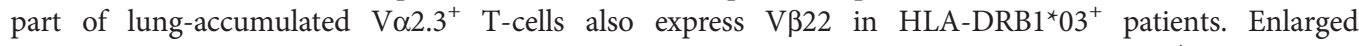
populations of T-cells expressing both V $\alpha 2.3$ and $\mathrm{V} \beta 22$ were identified in HLA-DRB $1^{\star} 03^{+}$patients, but not in HLA-DRB1 ${ }^{\star} 03^{-}$patients (with the exception of moderate increases in HLA-DRB3 ${ }^{\star} 01^{+}$patients). Analyses of cell surface markers CD69 and CD27 suggested significantly higher levels of $\mathrm{V} \alpha 2.3^{+} \mathrm{V} \beta 22^{+}$ T-cells to be activated, and also to be differentiated to a higher degree compared to their $\mathrm{V} \alpha 2.3^{-} \mathrm{V} \beta 22^{-}$ $\mathrm{CD}^{+} \mathrm{T}$-cells counterparts, likely reflecting antigenic stimulation. Alternatively, the high CD69 expression reflects a tissue-resident memory T-cell phenotype, suggested to be of importance for human tissue-specific immune and inflammatory diseases [25].

Finally, molecular modelling pinpointed unique features of the HLA-DRB1 ${ }^{\star} 03$ molecule and its interaction with specific residues of the $\mathrm{V} \alpha 2.3^{+} \mathrm{V} \beta 22^{+} \mathrm{TCR}$. This model also provided molecular insight into the 

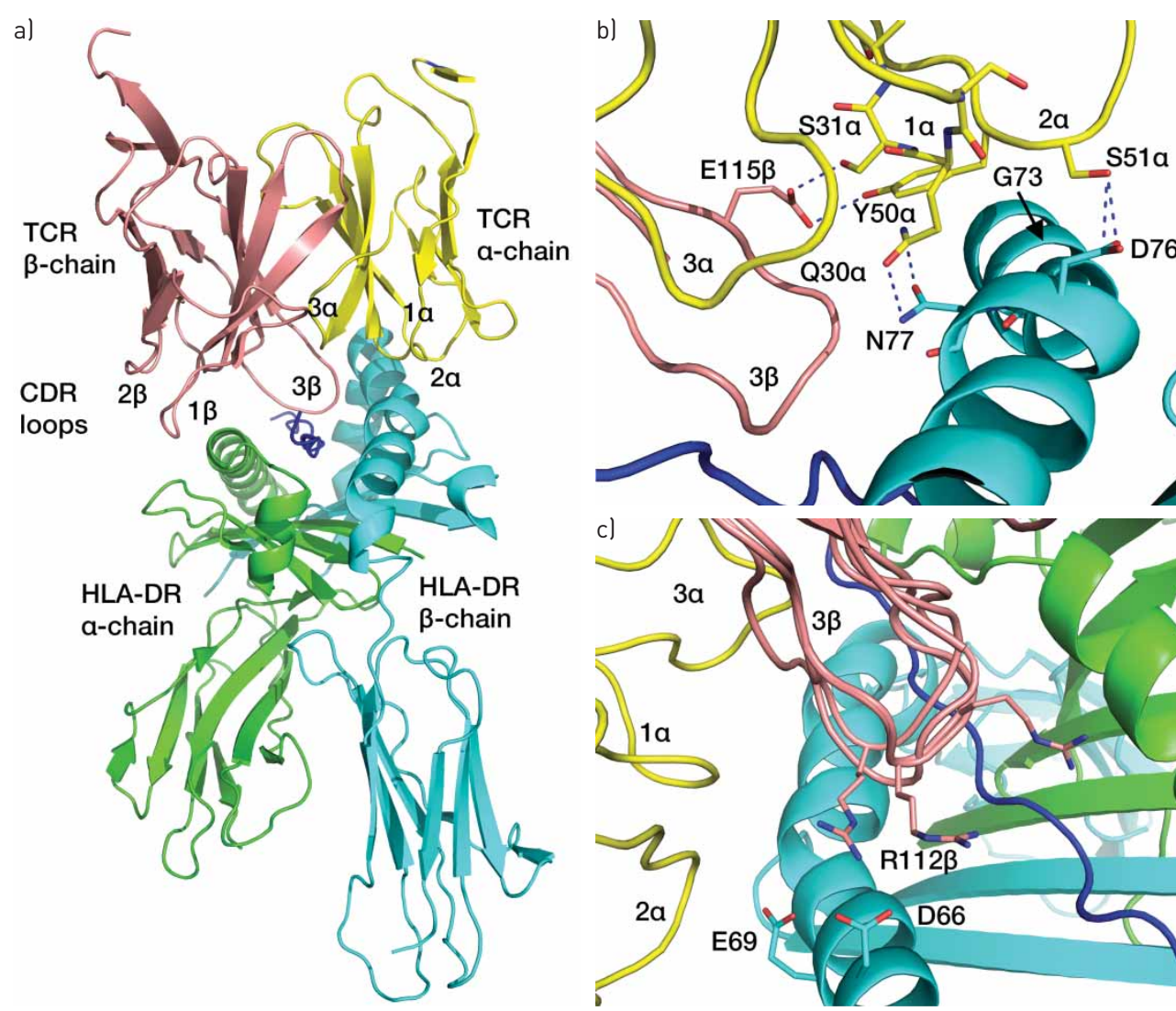

$51 a$
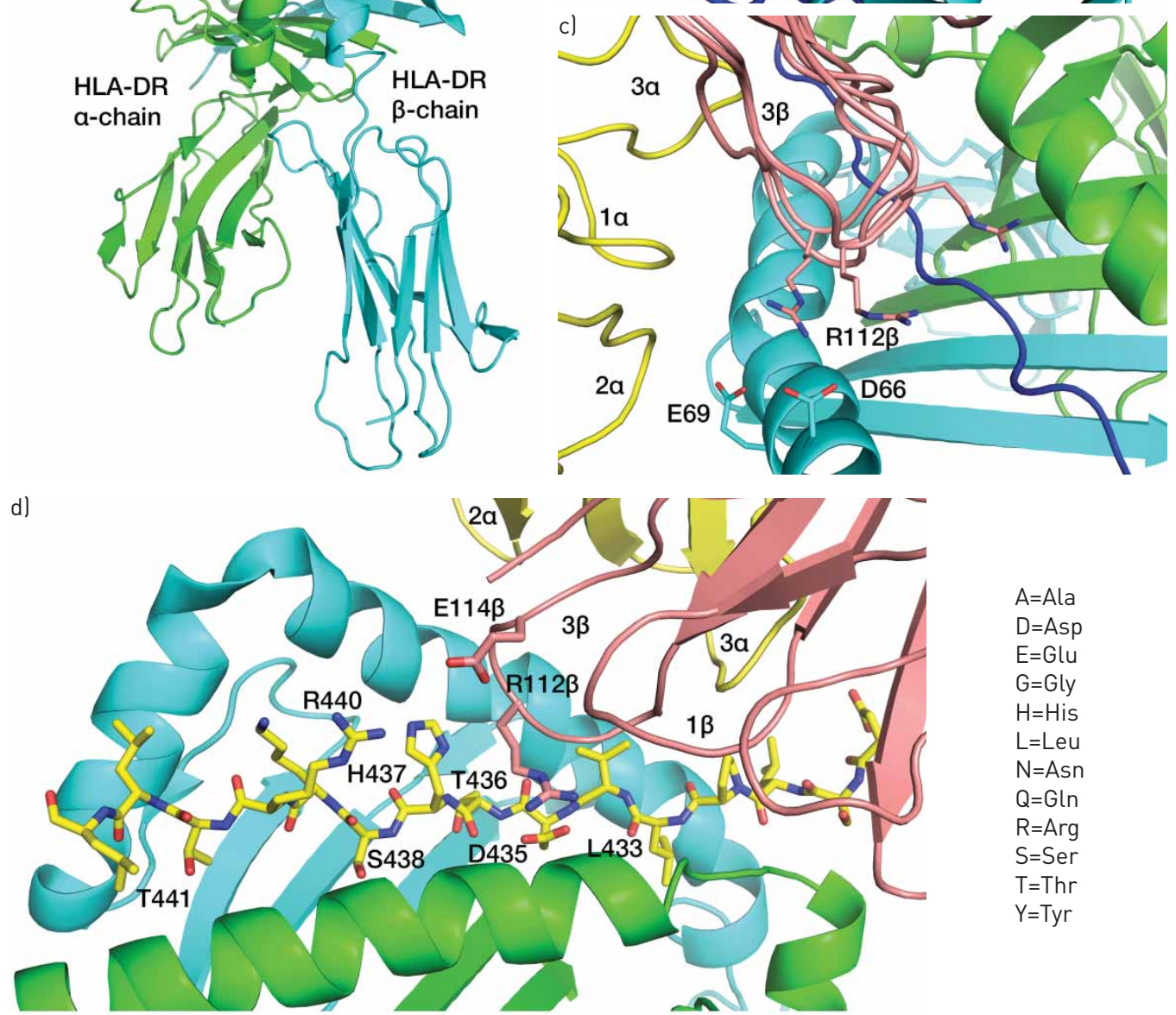

FIGURE 4 Conserved T-cell receptor (TCR) CDR3 $\beta$ residues interact with specific HLA and peptide residues, and preferentially select for V $\alpha 2.3$ chains. a) Overall ribbon representation of a representative three-dimensional structure of a ternary V $\alpha 2.3 / \mathrm{V} \beta 22 \mathrm{TCR} / \mathrm{DRB} 1 * 03 /$ peptide complex. TCR $\alpha$ and $\beta$ chains are in yellow and pink, respectively. CDR $1 \alpha$, CDR $2 \alpha, \operatorname{CDR} 3 \alpha, \operatorname{CDR} 1 \beta, \operatorname{CDR} 2 \beta$ and CDR3 $\beta$ regions are indicated as $1 \alpha, 2 \alpha, 3 \alpha, 1 \beta$, $2 \beta$ and $3 \beta$, respectively. HLA $\alpha$ and $\beta$ chains are in green and light blue, respectively. The peptide bound inside the HLA binding groove is in violet. b) HLA-DRB $1 * 03$ residues Gly73 and Asn77 could be responsible for specific selection of V $\alpha 2.3$ TCR $\alpha$ chains. The HLA residue Gly73 allows for the CDR $1 \alpha$ and CDR2 $\alpha$ loops to come closer to the HLA heavy chain, possibly resulting in interactions between TCR residues Gln30 and Ser51 and HLA residues Asn77 and Asp76, respectively. Furthermore, a molecular model of the V $\beta 22$ TCR CDR3 loop, found in patient 4, sequence 1 (CASSGGHGKGEQFF), indicates that TCR residue Glu115 (present in nine out of 18 sequences) is localised too far away from the peptide. Instead, this residue can form hydrogen bonds with residues Ser31 and Tyr50 localised on CDR1 $\alpha$ and CDR2 $\alpha$, respectively, possibly selecting for a class of TCR $\alpha$ chain such as V $\alpha 2.3$. c) The conformation of CDR3 $\beta$ loops depends on their length and amino acid compositions. However, the positively charged arginine residue Arg, found in a majority of V $\beta 22$ TCR chains, at either position 112 or 113 , is always localised at the top of the loop, independently of the CDR conformations. Residue Arg112/113 can thus interact either with conserved HLA class II $\beta$ chain residues such as Glu69 or Asp66, or with a negatively charged residue within the middle part of the presented peptide. $d$ ) The three-dimensional model indicates that the vimentin-derived peptide Vim429-443 DSLPLVDTHSKRTLL can bind efficiently to HLA-DRB1*03 by making use of residues Leu433, Thr436, Ser438 and Thr441 as anchor positions, occupying pockets 1, 4,6 and 9, respectively. Furthermore, a molecular model of the V $\beta 22$ TCR CDR3 $\beta$ loop, found in patient 1, sequence 1 (CASSEQGRGETQYF), reveals that the TCR residue Glu114 (present in five out of 18 sequences) can form a salt bridge with a positively charged residue, such as the arginine localised at position 8 in Vim429-443 (Arg440). The same TCR model also indicates that the TCR residue Arg112 may interact with a negatively charged peptide residue such as Asp435 in Vim429-443. 
preferential pairing of $\mathrm{V} \alpha 2.3$ with $\mathrm{V} \beta 22$, as well as with $\mathrm{HLA}-\mathrm{DRB} 1^{\star} 03$, and the ideal properties of this complex for accommodation of a potential antigenic peptide derived from cytoskeletal protein vimentin.

$\mathrm{V} \alpha 2.3^{+} \mathrm{V} \beta 22^{+} \mathrm{T}$-cells may have an enhanced capacity to recognise HLA-DRB1 ${ }^{\star} 03$-epitope complexes, explaining their accumulation in the lungs of HLA-DRB1 ${ }^{\star} 03^{+}$patients. In a recent study, we found that $\mathrm{V} \alpha 2.3^{+} \mathrm{T}$-cells accumulate in BAL fluid but remain at normal levels in regional lymph nodes and blood, suggesting inhalation of a presumed antigen [26]. Given that $21 \%$ (median) of lung-accumulated $\operatorname{Vo} 2.3^{+}$ $\mathrm{T}$-cells in HLA-DRB ${ }^{\star} 03^{+}$patients also express V 322 , our previous studies focusing on $\mathrm{V} \alpha 2.3^{+} \mathrm{T}$-cells alone might have overlooked differences in specificity and functional mechanisms, such as cytokine production and activation marker expression, between different $\mathrm{V} \alpha 2.3^{+} \mathrm{T}$-cell populations. Considering the co-expression of $\mathrm{V} \beta 22$, antigen specificity and effector cell functionality can be studied in further detail, taking both the $\mathrm{V} \alpha$ and $\mathrm{V} \beta$ gene segments within these lung-accumulated T-cells into account.

The identification of a few dominant TCR V $\alpha 2.3$ and V $\beta 22$ sequences in each patient demonstrates a high degree of $\mathrm{V} \alpha 2.3^{+} \mathrm{V} \beta 22^{+} \mathrm{T}$-cell clonality in the lungs, strongly implicating specific antigen recognition in pulmonary sarcoidosis. These clones could be useful to further investigate candidate antigens, such as ESAT-6 [27] or mKatG [28], as well as to unravel molecular details underlying how such TCRs interact with HLA-DRB ${ }^{\star} 03$-peptide complexes. The potential existence of specific antigens restricted to HLA-DRB ${ }^{\star} 03$ is further supported by our findings of identical and near-identical TCR $\alpha$ chain sequences in different patients as well as of similar amino acids at distinct positions within the TCR $\beta$ chains. Also, the fact that different nucleotide sequences code for the same amino acid residues indicates preferential selection at the protein level, as in the case of antigen recognition. Altogether, these findings strongly support our hypothesis that $\mathrm{V} \alpha 2.3^{+} \mathrm{V} \beta 22^{+}$lung $\mathrm{T}$-cells recognise and proliferate in response to sarcoidosis-associated and DRB1*0301-restricted antigens.

The inclusion of a three-dimensional molecular model for elucidating the possible arrangement of specific residues within the different $\mathrm{CDR}$ loops allowed us to establish common features of recognition in the $\mathrm{V} \alpha 2.3 / \mathrm{V} \beta 22 \mathrm{TCR} / \mathrm{HLA}-\mathrm{DRB} 1^{\star} 03$ molecular complex. It is well known that sarcoidosis, and especially variants with good prognosis such as Löfgren's syndrome, strongly associate with HLA-DRB ${ }^{\star} 0301$ and HLA-DRB $3^{\star} 0101$ alleles $[29,30]$. Whether such a good prognosis depends on the HLA molecules themselves, linkage to other gene variants, or their connection to lung-accumulated $\mathrm{V} \alpha 2.3^{+} \mathrm{V} \beta 22^{+} \mathrm{T}$-cells that may be particularly efficient in eliminating antigens [31], remains to be elucidated. It is worth noting, however, that the more $\mathrm{V} \alpha 2.3^{+}$cells in BAL fluid, the better the prognosis [32].

Although the majority of residues that differ between HLA-DRB1 ${ }^{\star} 0301$ and other HLA molecules are found within the peptide-binding cleft, alignment reveals that two specific residues, Gly73 and Asn77, localised on the HLA-molecule far from the presented epitope, are readily available for interaction with TCR residues. Interestingly, these positions are identical in HLA-DRB $3^{\star} 0101$, which is also known to correlate with assembly of $\mathrm{V} \alpha 2.3^{+} \mathrm{T}$-cells in the lungs [11], and to some degree with $\mathrm{V} \alpha 2.3^{+} \mathrm{V} \beta 22^{+} \mathrm{T}$-cells. We therefore hypothesise that Gly73 and Asn77 residues, in combination with specific, not yet identified, epitopes, could be responsible for attracting TCR V $\alpha 2.3^{+}$T-cells to the lungs, since residues prominent among all the analysed CDR1 $\alpha$ and CDR2 $\alpha$ loops are closely positioned to both Gly73 and Asn77, as illustrated in figure 4a.

In addition, the repeated identical or near-identical CDR3 regions of V $\alpha 2.3$-expressing T-cells can interact with the HLA-DRB1 ${ }^{\star} 03$ molecule (figure 4 ). The charged amino acids found at distinct positions in a majority of $\mathrm{V} \beta 22$ CDR3 regions enable direct interaction with a peptide antigen harbouring charged amino acids at position 5 and 7, respectively. This suggests that the V $\alpha 2.3$ gene segment allows for close association with HLA-DRB1 ${ }^{\star} 03$ (or HLA-DRB3 ${ }^{\star} 01$ ) molecules, while V 322 CDR3 regions directly recognise the actual antigenic peptide. Accordingly, the V $\alpha 2.3$ gene segment may pair with other, still unidentified, $\mathrm{V} \beta$ segments to recognise other antigenic peptides in complex with HLA-DRB $1{ }^{*} 03$ molecules; this may also explain the higher inter-patient similarity of V $\alpha 2.3$ compared with V $\beta 22$ CDR3 regions. In addition, since the charged V $\beta 22$ amino acids at position 115 are located far away from the peptide, they may alternatively interact directly with a correspondingly charged amino acid within V $\alpha 2.3$ CDR1 or CDR2 regions, and thus to some extent explain the preferential pairing of V $\alpha 2.3$ with V $\beta 22$.

Based on the strong TCR-HLA association presented here, we assessed the binding capacity of potential peptide antigens to the TCR-HLA complex. Interestingly, a previously identified vimentin-derived peptide, Vim429-443 (DSLPLVDTHSKRTLL), eluted from HLA-DR molecules of pooled BAL cells from HLA-DRB $1^{*} 03^{+}$sarcoidosis patients [24], matches perfectly into both the HLA peptide-binding pocket and the TCR V 322 CDR3 loop in the proposed molecular model. The same vimentin peptide has been found to stimulate peripheral blood T-cells of HLA-DRB $1^{\star} 03^{+}$sarcoidosis patients [33].

The intracytoplasmic protein vimentin has been implicated as an auto-antigen in other diseases. Renal inflammation is a frequent and severe manifestation of systemic lupus erythematosus, with tubulointerstitial 
inflammation (TII) as a common variant. Vimentin was recently shown to be the main targeted auto-antigen in TII [34]. An altered and increased expression of vimentin locally in the kidneys, as well as an association between high titres of serum anti-vimentin autoantibodies and disease severity, was observed in patients with TII, implicating both systemic and local autoimmunity. As vimentin is a basic protein and can be secreted by activated macrophages, it may be abundant in inflammatory conditions [35]. Vimentin can bind to receptors (dectin 1) expressed on dendritic cells, macrophages and B cells, thereby loading and activating antigen-presenting cells [36]. Also, vimentin can be post-translationally modified and thereby become an auto-antigenic target, as shown in rheumatoid arthritis [37]. Whether sarcoidosis may be an autoimmune disease or not, or have an autoimmune component, is still not possible to conclude. While both associations with certain HLA types and reactivity against the self-protein vimentin are in line with the concept of autoimmunity, a seasonal distribution of disease onset [30], as well as the fact that sarcoidosis (especially Löfgren's syndrome) normally runs a self-limiting disease course, would argue against. Moreover, there are examples of transient autoimmunity following infection [38, 39], consistent with our previous finding that strong anti-vimentin $\mathrm{T}$-cell responses were absent in patients after recovery [33].

The theoretical nature of the molecular model is a limitation to this study, and future functional analyses will aim to investigate any antigenic potential of vimentin. To this end, we plan to study B as well as T-cell responses against different forms of vimentin (recombinant protein, individual peptides, post-translationally modified peptides etc.). T-cell cytokine production and proliferation will be analysed using ELISpot and flow cytometry, and we will assess presence of any vimentin-specific Ig subclasses in both BAL fluid and serum. All patients will be HLA-typed, and to identify any associations of T and B cell responses with clinical features, a careful clinical characterisation, including monitoring of disease course and separate examination of specific subgroups e.g. Löfgren's syndrome patients, will have to be performed. However, we need also to consider the possibility that the ideal fit of vimentin into the peptide-binding cleft of HLA-DRB1 ${ }^{\star} 03$ molecules reflects molecular mimicry, and that a "true" sarcoidosis antigen is in reality a foreign agent such as a microorganism.

In conclusion, the novel identification of lung-accumulated $\mathrm{V} \alpha 2.3^{+} \mathrm{V} \beta 22^{+} \mathrm{T}$-cell clones in strict association with HLA-DRB1 ${ }^{\star} 03$ molecules, and inter-patient similarities between both TCR $\alpha$ and $\beta$ chain sequences, strongly indicate recognition of a specific antigen in these patients. Furthermore, modelling of the TCR-HLA complex suggests a vimentin-derived peptide as a possible autoantigen in sarcoidosis given its potential for binding to the HLA-DRB1 ${ }^{\star} 03$ molecule and interaction with TCR CDR $3 \beta$ residues. In our continuing search for a sarcoidosis-specific antigen, vimentin will be of particular interest for future studies.

\section{Acknowledgements}

The authors thank research nurses Heléne Blomqvist, Margitha Dahl and Gunnel de Forest as well as biomedical analyst Benita Dahlberg for skilful assistance with sample collections and preparations. Also, we would like to acknowledge support from Science for Life Laboratory, the National Genomics Infrastructure (NGI) and Uppmax for providing assistance in massively parallel sequencing and computational infrastructure.

\section{References}

1 Rudolph MG, Stanfield RL, Wilson IA. How TCRs bind MHCs, peptides, and coreceptors. Annu Rev Immunol 2006; 24: 419-466.

2 Forman JD, Klein JT, Silver RF, et al. Selective activation and accumulation of oligoclonal V beta-specific T cells in active pulmonary sarcoidosis. J Clin Investig 1994; 94: 1533-1542.

3 Forrester JM, Wang Y, Ricalton N, et al. TCR expression of activated T cell clones in the lungs of patients with pulmonary sarcoidosis. J Immunol 1994; 153: 4291-4302.

4 Grunewald J, Olerup O, Persson U, et al. T-cell receptor variable region gene usage by CD4+ and CD8+ T cells in bronchoalveolar lavage fluid and peripheral blood of sarcoidosis patients. Proc Natl Acad Sci USA 1994; 91: 4965-4969.

5 Katchar K, Wahlstrom J, Eklund A, et al. Highly activated T-cell receptor AV2S3(+) CD4(+) lung T-cell expansions in pulmonary sarcoidosis. Am J Respir Crit Care Med 2001; 163: 1540-1545.

6 Idali F, Wahlstrom J, Dahlberg B, et al. Altered expression of T cell immunoglobulin-mucin (TIM) molecules in bronchoalveolar lavage CD4+ T cells in sarcoidosis. Respir Res 2009; 10: 42.

7 Wahlstrom J, Katchar K, Wigzell H, et al. Analysis of intracellular cytokines in CD4+ and CD8+ lung and blood T cells in sarcoidosis. Am J Respir Crit Care Med 2001; 163: 115-121.

8 Ten Berge B, Paats MS, Bergen IM, et al. Increased IL-17A expression in granulomas and in circulating memory T cells in sarcoidosis. Rheumatology (Oxford) 2012; 51: 37-46.

9 Idali F, Wahlstrom J, Muller-Suur C, et al. Analysis of regulatory T cell associated forkhead box P3 expression in the lungs of patients with sarcoidosis. Clin Exp Immunol 2008; 152: 127-137.

10 Miyara M, Amoura Z, Parizot C, et al. The immune paradox of sarcoidosis and regulatory T cells. J Exp Med 2006; 203: 359-370.

11 Grunewald J, Wahlstrom J, Berlin M, et al. Lung restricted T cell receptor AV2S3+ CD4+ T cell expansions in sarcoidosis patients with a shared HLA-DRbeta chain conformation. Thorax 2002; 57: 348-352.

12 Grunewald J. Focusing on the human T cell receptor for antigen. Sarcoidosis 1994; 11: 61-65.

13 Grunewald J, Eklund A, Wahlstrom J. CD4+ T cells in sarcoidosis: targets and tools. Expert Rev Clin Immunol 2006; 2: 877-886. 
14 Grunewald J, Hultman T, Bucht A, et al. Restricted usage of T cell receptor V alpha/J alpha gene segments with different nucleotide but identical amino acid sequences in HLA-DR3+ sarcoidosis patients. Mol Med 1995; 1: $287-296$

15 Nagvekar N, Corlett L, Jacobson LW, et al. Scanning a DRB3*0101 (DR52a)-restricted epitope cross-presented by DR3: overlapping natural and artificial determinants in the human acetylcholine receptor. J Immunol 1999; 162: 4079-4087.

16 Ahlgren KM, Ruckdeschel T, Eklund A, et al. T cell receptor-Vbeta repertoires in lung and blood CD4+ and CD8+ T cells of pulmonary sarcoidosis patients. BMC Pulm Med 2014; 14: 50.

17 Olsen HH, Grunewald J, Tornling G, et al. Bronchoalveolar lavage results are independent of season, age, gender and collection site. PLoS One 2012; 7: e43644.

18 Costabel U, Hunninghake GW. ATS/ERS/WASOG statement on sarcoidosis. Sarcoidosis Statement Committee. American Thoracic Society. European Respiratory Society. World Association for Sarcoidosis and Other Granulomatous Disorders. Eur Respir J 1999; 14: 735-737.

19 Grabherr MG, Haas BJ, Yassour M, et al. Full-length transcriptome assembly from RNA-Seq data without a reference genome. Nat Biotechnol 2011; 29: 644-652.

20 Li B, Dewey CN. RSEM: accurate transcript quantification from RNA-Seq data with or without a reference genome. BMC Bioinformatics 2011; 12: 323.

21 Ehrenmann F, Kaas Q, Lefranc MP. IMGT/3Dstructure-DB and IMGT/DomainGapAlign: a database and a tool for immunoglobulins or antibodies, T cell receptors, MHC, IgSF and MhcSF. Nucleic Acids Res 2010; 38 : D301-D307.

22 Emsley P, Lohkamp B, Scott WG, et al. Features and development of Coot. Acta Crystallogr D Biol Crystallogr 2010; 66: 486-501.

23 Lefranc MP. IMGT, The International ImMunoGeneTics Information System, http://imgt.cines.fr. Methods Mol Biol 2004; 248: 27-49.

24 Wahlstrom J, Dengjel J, Persson B, et al. Identification of HLA-DR-bound peptides presented by human bronchoalveolar lavage cells in sarcoidosis. J Clin Invest 2007; 117: 3576-3582.

25 Park CO, Kupper TS. The emerging role of resident memory $\mathrm{T}$ cells in protective immunity and inflammatory disease. Nat Med 2015; 21: 688-697.

26 Darlington P, Haugom-Olsen H, von Sivers K, et al. T-cell phenotypes in bronchoalveolar lavage fluid, blood and lymph nodes in pulmonary sarcoidosis-indication for an airborne antigen as the triggering factor in sarcoidosis. J Intern Med 2012; 272: 465-471.

27 Oswald-Richter K, Sato H, Hajizadeh R, et al. Mycobacterial ESAT-6 and katG are recognized by sarcoidosis CD4+ T cells when presented by the American sarcoidosis susceptibility allele, DRB1*1101. J Clin Immunol 2010; 30: $157-166$

28 Song Z, Marzilli L, Greenlee BM, et al. Mycobacterial catalase-peroxidase is a tissue antigen and target of the adaptive immune response in systemic sarcoidosis. J Exp Med 2005; 201: 755-767.

29 Grunewald J. Review: role of genetics in susceptibility and outcome of sarcoidosis. Semin Respir Crit Care Med 2010; 31: 380-389.

30 Grunewald J, Eklund A. Lofgren's syndrome: human leukocyte antigen strongly influences the disease course. Am J Respir Crit Care Med 2009; 179: 307-312.

31 Wiken M, Ostadkarampour M, Eklund A, et al. Antigen-specific multifunctional T-cells in sarcoidosis patients with Lofgren's syndrome. Eur Respir J 2012; 40: 110-121.

32 Grunewald J, Berlin M, Olerup O, et al. Lung T-helper cells expressing T-cell receptor AV2S3 associate with clinical features of pulmonary sarcoidosis. Am J Respir Crit Care Med 2000; 161: 814-818.

33 Wahlstrom J, Dengjel J, Winqvist $\mathrm{O}$, et al. Autoimmune T cell responses to antigenic peptides presented by bronchoalveolar lavage cell HLA-DR molecules in sarcoidosis. Clin Immunol 2009; 133: 353-363.

34 Kinloch AJ, Chang A, Ko K, et al. Vimentin is a dominant target of in situ humoral immunity in human lupus tubulointerstitial nephritis. Arthritis Rheum 2014; 66: 3359-3370.

35 Mor-Vaknin N, Punturieri A, Sitwala K, et al. Vimentin is secreted by activated macrophages. Nat Cell Biol 2003; 5: 59-63.

36 Thiagarajan PS, Yakubenko VP, Elsori DH, et al. Vimentin is an endogenous ligand for the pattern recognition receptor Dectin-1. Cardiovasc Res 2013; 99: 494-504.

37 Bang H, Egerer K, Gauliard A, et al. Mutation and citrullination modifies vimentin to a novel autoantigen for rheumatoid arthritis. Arthritis Rheum 2007; 56: 2503-2511.

38 Cervera R, Asherson RA. Antiphospholipid syndrome associated with infections: clinical and microbiological characteristics. Immunobiology 2005; 210: 735-741.

39 Gudjonsson JE, Johnston A, Sigmundsdottir H, et al. Immunopathogenic mechanisms in psoriasis. Clin Exp Immunol 2004; 135: 1-8. 